\title{
NUESTROS AÑOS LEFORT. NOTAS SOBRE LA RECEPCIÓN DE CLAUDE LEFORT EN LA ARGENTINA DE LA TRANSICIÓN A LA DEMOCRACIA ${ }^{1}$
}

\author{
Claudia Hilb²
}

Esta breve presentación no tiene mucha mayor pretensión que la de constituir un homenaje a Claude Lefort, quien sin duda alguna marcó de manera absolutamente determinante mi trayectoria intelectual, y la de algunos pocos otros colegas en Argentina, a partir de principios de la década del '80. Mi propósito se limita a reseñar de qué manera se produjo la recepción de la obra de Lefort en Argentina en esa década, quiénes, en qué condiciones, desde qué cruces o intereses, empezaron a leerlo, a prestarle atención, a pensar con él, o contra él, o a través de él, y lo incluyeron explícitamente o no tanto en sus textos, en sus referencias, en sus clases.

Tengo el temor razonablemente fundado de que algunas de las cosas que voy a contar tengan un interés reducido para quienes no conozcan los grandes rasgos del mapa intelectual de la Argentina, y sobre todo de BsAs, de los años '80 (y la verdad, ¿por qué habrían de conocerlo?). Pero dada la naturaleza de este ejercicio, tendré que dar una cantidad de nombres propios, que en el medio intelectual argentino hablan por sí solos o casi, y que trataré de situar cada vez aquí. Y temo también que deberé referirme a mí misma más de lo que cualquiera considerará decente - pero en fin, no puedo obviar que fui de quienes participaron con entusiasmo de esa lectura y difusión, aún limitada, de Lefort en Argentina en los '80.

\footnotetext{
${ }^{1}$ Dossiê Claude Lefort: esse texto é parte do dossiê publicado a partir das comunicações realizadas no Colóquio Internacional Claude Lefort: a invenção democrática hoje, realizado na Universidade de São Paulo entre os dias 13 e 16 de outubro de 2015.

${ }^{2}$ Claudia Hilb - IIGG (Facultad de Ciencias Sociales - UBA) / Conicet. Agradezco a Carlos Altamirano, Waldo Ansaldi, Fernando Calderón, Isidoro Cheresky, Emilio de Ipola, Alicia Farinati, Luis Alberto Quevedo y Maristella Svampa por haber accedido a conversar largamente conmigo en ocasión de la preparación de este trabajo, y a Horacio González, Cristina Hurtado, Daniel Lutzky, Chantal Mouffe, Eduardo Rinesi, Héctor Schmucler y Susana Villavicencio por haber respondido a las preguntas que les hice por vía de correo electrónico.
} 
Entonces, para ir al grano: trazando el mapa, que creo resulta bastante exhaustivo, de los argentinos que en los años '80 leímos a Lefort y trasladamos algunos de sus tópicos a nuestros debates, nuestros escritos, nuestras clases o nuestras preocupaciones, podemos para comenzar hacer una distinción geográfica. En esa distinción podemos identificar en primer lugar a quienes, como Isidoro Cheresky, Daniel Lutzky o yo misma, vivimos en Paris durante y a causa de la dictadura militar y asistimos al seminario de Lefort en la EHESS a partir de la primera mitad de los '80, a Luis Alberto Quevedo, que residió en Paris entre 1984 y 1986 para realizar su DEA y asistió también al seminario, o un poco más tarde, a Maristella Svampa, que hizo su DEA bajo la dirección de Lefort entre 1987 y 1989. (También podría mencionar aquí a Fernando Calderón, no argentino sino boliviano, quien en los '70 hacía su tesis doctoral en el entorno de Alain Touraine, pero por razones que espero justificadas incluiré a Calderón cuando me ocupe de la recepción desde Argentina). Creo poder afirmar que para Isidoro Cheresky y para mí, y de manera menos marcada, probablemente, para Lutzky, que proveníamos de experiencias de militancia política, aunque distintas entre ellas - comunista, de la izquierda armada y maoista, respectivamente - el encuentro con la obra de Lefort se dio en la misma clave en la que Lefort se insertaba entonces esencialmente - o eso me parecía a mí - en el debate francés, esto es, en la clave de un pensamiento en ruptura con la izquierda tradicional, de crítica implacable al totalitarismo comunista, que ofrecía a la vez una posibilidad de repensar, desde esa crítica, la democracia, el pluralismo, la libertad. No quiero dejar de mencionar que yo llegué al seminario de Lefort en 1982 a través de Cristina Hurtado, una profesora chilena exiliada que conocí en un curso que Cristina dictaba con Elizabeth Souza Lobo ${ }^{3}$ en Paris VIII, y que asistí al seminario de Lefort hasta mi regreso a la Argentina en 1987; Isidoro Cheresky, primero mi profesor en el $\mathrm{IHEAL}^{4}$ en ese mismo año 1982, y luego amigo y colega, llegó al seminario a través mío, y lo mismo sucedió con Daniel Lutzky, a quien había conocido en el medio de exiliados, a través de amigos en común, cuando llegó a Francia tras salir de prisión. En cuanto a Luis Alberto Quevedo, hoy director de Flacso pero entonces joven (como todos nosotros) investigador del CEDES, ${ }^{5}$ uno de los centros que bajo la Dictadura cobijaron lo que

\footnotetext{
3 A fines de los años '70 Cristina Hurtado dictaba un curso de sociología junto con Elizabeth Souza Lobo en la Universidad de Paris VIII. Ambas, junto con Marco Aurelio Garcia, marido de Elizabeth, marcaron de manera más decisiva de lo que ellos mismos supieron mi alejamiento de la izquierda más tradicional y mi apertura intelectual hacia una izquierda no dogmática y democrática.

${ }^{4}$ Institut de Hautes Études sur l'Amérique Latine, Universidad de la Sorbonne Nouvelle-Paris III.

${ }^{5}$ Centro de Estudios de Estado y Sociedad.
} 
pudo hacerse en el campo de la investigación en Ciencias Sociales, y que había sido colaborador de Adolfo Pérez Esquivel en Argentina, y que viajó a Francia para hacer su DEA en 1984, o sea ya en época de democracia, sin duda conoció la existencia de Lefort a través de Cheresky y de mí, y lo frecuentó durante los dos años de su estadía. Para Luis Alberto el interés de la obra de Lefort residía no tanto como para nosotros en el camino que nos había proporcionado para dar cauce a nuestra ruptura con la izquierda tradicional, la experiencia comunista y un marxismo convertido en filosofía de la historia, y para pensar la democracia, los derechos y la libertad, sino principalmente en la posibilidad más específica de pensar la democracia, ahora revalorizada de repente en Argentina, por fuera del modo en que esta era traída al debate por las corrientes institucionalistas norteamericanas. Además, por supuesto, de la apertura al pensamiento que significaba la frecuentación de los seminarios semanales de alguien al que, como me señaló Quevedo, “se lo veía pensar".

Como marca visible del impacto que tuvo la frecuentación de Lefort sobre nuestros modos de pensar, cabe señalar que Lutzky y yo citamos a Lefort en varias oportunidades en nuestro librito La nueva iqquierda argentina 1960-1976 escrito en 1982-83 en Francia, y publicado en 1984 en Buenos Aires (probablemente sean las primeras citas de Lefort en Argentina). Isidoro Cheresky, que había sido colaborador de Nikos Poulantzas durante los '70, y que a comienzos de los 80 era profesor del IHEAL, comienza como decía a frecuentar el seminario de Lefort en 1982 o 1983, y a partir de 1987, ya profesor regular de la Universidad de Buenos Aires, incorpora a Lefort a la bibliografía de su materia... en la que participamos como profesores adjunto y auxiliar, respectivamente, Luis Alberto Quevedo y yo. El propio Cheresky participará en 1987 del Coloquio "Democracia, totalitarismo y socialismo", organizado en la EHESS por el Centre Raymond Aron y Clacso, del cual saldrá el libro Socialismo, autoritarismo y democracia, ${ }^{6}$ y unos años más tarde, en enero de 1992, participará también de un encuentro de intelectuales en homenaje a Lefort, organizado por la Revista Esprit en el Centro Pompidou, y del cual surgirá el libro La démocratie à l'oewvre. Autour de Claude Lefort, publicado en 1993 bajo la dirección de Claude Habib y Claude Mouchard - libro que incluye un artículo de Cheresky

\footnotetext{
${ }^{6}$ Calderón, Fernando (comp.), Socialismo, autoritarismo y democracia, Lima, IEP/Clacso, 1989. Calderón, por entonces director de Clacso, escribe en el prólogo: "El presente libro es el resultado de una idea compartida y emprendida hace ya tres años juntamente con Francois Furet, idea que se plasmó en un coloquio realizado en la Escuela de Altos Estudios de Ciencias Sociales en París, en el que además de los autores participaron Claude Lefort, Daniel Pecaut, Isidoro Cheresky, Francisco Delich y Francisco Weffort.” Esos autores son, además del propio Calderón, François Furet, Pierre Rosanvallon, Norbert Lechner, Mario Dos Santos, Alain Touraine, François-Xavier Guerra, Jose Arthur Giannotti y José Aricó.
} 
(publicado también en Argentina en la Revista Punto de Vista, $N^{\circ} 43$, en 1992), sobre la revalorización de los derechos humanos, de fuerte impronta lefortiana. ${ }^{7}$ Por esos mismos años 1988-90, Luis Alberto Quevedo y yo tomamos a cargo, por separado, otras materias en la misma Facultad de Ciencias Sociales de la Universidad de Buenos Aires, y seguimos incluyendo (sin interrupción hasta hoy, en ambos casos) textos de Lefort en el programa. Agreguemos a este relevamiento por así decir "europeo" que por esa misma época dos libros que dejaron una fuerte impronta en las ciencias sociales en Argentina citaban también a un Claude Lefort por entonces casi desconocido en esas tierras: uno, Hegemony and Socialist Strategy, ${ }^{8}$ de Ernesto Laclau y Chantal Mouffe, publicado por Verso en Londres en 1985 - cabe mencionar que Chantal asistía al seminario de Lefort cuando se encontraba en Paris y que como me lo confirma Chantal, la referencia a Lefort es obra suya; el otro, Perón o Muerte, de Silvia Sigal y Eliseo Verón, ambos residentes en Francia, que apareció en Legasa en $1986 .{ }^{10}$ Por fin, es importante señalar que si lo hasta ahora descripto forma, de algún modo, una constelación de gente que se conoce, se frecuenta, y participa a grandes rasgos del mismo medio en Paris y luego en Buenos Aires, Maristella Svampa - unos 6 o 7 años más joven que Quevedo, Lutzky y yo - ya pertenece a otra constelación, y su llegada al seminario de Lefort se produce en 1987-88, sin mayor relación con ninguno de los anteriores; licenciada en filosofía por la Universidad de Córdoba, Maristella conoce allí, a través de gente cercana, la existencia de Socialisme ou Barbarie y se entusiasma con esa aventura intelectual. No obstante, el nombre de Lefort, recuerda hoy, al que accedió por esa vía, se le volvía a aparecer de golpe en lecturas argentinas, en el libro de Sigal y Verón, como así también en el librito de Lutzky y mío, a los que me he referido. Decidida a realizar en Francia su doctorado, cuyo tema versaba sobre el Facundo (o más exactamente, sobre Civilización y Barbarie en el Facundo de Domingo Faustino Sarmiento), e impulsada a atreverse a ello por Silvia Sigal, pidió una cita con Lefort y logró que este tomara a su cargo la dirección de su DEA en la EHESS. (A modo de anécdota: cuenta Maristella que años después creyó

\footnotetext{
${ }^{7}$ Habib, Claude et Claude Mouchard (eds), La démocratie à l'oeuvre. Autour de Claude Lefort, Paris, Esprit, 1993. El libro retoma una parte de las intervenciones de dicha jornada, a los que agrega algunos textos más (agradezco esta información a Claude Habib). Observamos que en su texto, Cheresky refiere al artículo "Droits de 1'Homme et État Providence" de Claude Lefort.

${ }^{8}$ Laclau, Ernesto and Chantal Mouffe, Hegemony and Socialist Strategy, London, Verso, 1985.

${ }^{9}$ Chantal Mouffe me confirma, en un mail, que Ernesto Laclau no había por entonces aún leído a Lefort.

10 Sigal, Silvia y Verón, Eliseo, Perón o Muerte, Buenos Aires, Eudeba, 1986. Sin duda, aunque no fuera un autor particularmente ligado a sus intereses más inmediatos, Silvia Sigal y Eliseo Verón conocían la obra de Lefort en razón de la inmersión de ambos en el medio intelectual francés.
} 
entender cómo se había producido aquel acontecimiento inesperado. El suegro de Lefort, Marcel Bataillon, era el célebre autor de una traducción extraordinaria del Facundo, y ello, piensa, debió haber provocado el interés de Lefort en el tema.) Si bien el Lefort de los '80 no es ya el mismo que Maristella Svampa había leído en Socialismo o Barbarie, y si bien su deriva teórica no le es estrictamente afín, ${ }^{11}$ Maristella no sólo tiene un recuerdo luminoso de aquellos seminarios; la obra de Lefort tiene una presencia destacada en su tesis doctoral, y el propio Lefort formó parte del jurado de dicha tesis. Para completar el panorama, cabe por fin sumar a esta enumeración a Alicia Farinati, licenciada en filosofía por la UBA, residente en Paris entre 1967 y 1979 aproximadamente, que conocía la trayectoria de Lefort en Socialisme ou Barbarie, y quien asistió al seminario que este comenzó a dictar en la EHESS poco antes de su regreso a la Argentina, y que continuó frecuentando los cursos de Lefort, y a Lefort mismo, en sus sucesivos viajes a Francia. Alicia Farinati, profesora en la Facultad de Derecho de la UBA desde los años '80, incluyó tempranamente en la bibliografía de su materia artículos de Lefort, en particular, de Les formes de l'histoire y de Essais sur le politique.

Podemos luego, para seguir con la distinción geográfica, identificar a quienes conocieron a Lefort - o más precisamente a la obra lefortiana - en su exilio brasilero a fines de los setenta y principios de los ochenta. Sabemos que si la entrada de la obra lefortiana al debate en Argentina fue tardía y restringida, no sucedió lo mismo en Brasil. Así, los intelectuales argentinos allí radicados se encontraron, en general, con dicha obra antes de que lo hicieran cuando lo hicieron - sus pares en Argentina. Héctor Leis, quien realizó su doctorado en la Pontificia Universidad Católica de Rio de Janeiro durante su exilio, y fue más tarde Profesor del Departamento de Sociología y Ciencia Política de la Universidad Federal de Santa Catarina, parece haber encontrado ya entonces en la obra lefortiana una referencia importante para su reevaluación de la temática de los derechos humanos. Recientemente fallecido, Héctor siguió radicado en Brasil, aunque alternaba entre sus dos países y participaba de manera activa del debate intelectual en Argentina. Así, puede observarse que Leis cita a Lefort - a partir de la edición en portugués de L’invention démocratique - en el volumen 1 de El movimiento por los derechos

\footnotetext{
${ }^{11}$ En diálogo con Maristella, ella me dice que si bien esa deriva no le interesó tan particularmente, vista en la perspectiva de su trayectoria el tránsito de la crítica lefortiana del totalitarismo a la re-interrogación de la democracia se entiende perfectamente por fuera de una simple "conversión" al liberalismo. En realidad, advierte, su propia disputa a fines de los '80 y durante los '90 con ciertas corrientes intelectuales vernáculas, a grandes rasgos identificadas como socialdemócratas, no era tanto con Lefort mismo, sino con quienes hacían uso de él en Argentina en una perspectiva que parecía adosarlo de manera demasiado directa al liberalismo, o al olvido de las luchas sociales.
} 
bumanos y la politica argentina, publicado por el Centro Editor de América Latina en 1989. Asimismo, sabemos que Lefort estaba incluido en la bibliografía de la materia del curso introductorio a cargo de Leis en la UBA, en particular, una vez más, en referencia a la temática de los Derechos humanos. ${ }^{12}$ En cuanto a Horacio González, también exiliado en los '70 en Brasil, si bien, a diferencia de casi todos los hasta aquí mencionados él mismo está lejos de considerar relevante el impacto de la obra de Lefort en su trayectoria, no podemos dejar de señalar que González había accedido ya a fines de los '70 a la lectura de Lefort a través del círculo que rodeaba a Marilena Chaui; como es sabido, Las formas de la bistoria había aparecido en portugués en la editorial Brasiliense en 1979, apenas un año después de su aparición en francés, traducido entre otros por la propia Marilena. De esa lectura Horacio González recuerda en particular su interés por los textos sobre Marx, Merleau Ponty y Mauss, y recuerda asimismo haberlos incorporado a sus clases. González siguió leyendo a Lefort con interés desigual, aunque menciona también su interés particular por ¿Permanece lo teológico-político?, ${ }^{13}$ que incorporó alguna vez, posteriormente, a la bibliografía de sus materias. ${ }^{14}$ Por fin, cerrando este breve tránsito por Brasil, encontramos la mención de Lefort en un texto de José María Gómez, incluido en el libro La ética de la democracia coordinado por Waldo Ansaldi en 1985 - libro que posee la sorprendente particularidad de contener referencias a Lefort en tres textos, a saber el de Gómez, la introducción de Ansaldi, y un texto del politólogo alemán radicado en Chile, Norbert Lechner. ${ }^{15}$ Según he podido saber por Ansaldi, Gómez, quien había sido compañero de universidad del propio Ansaldi en Córdoba, se había radicado en Rio de Janeiro tras realizar su doctorado en Lovaina, y participaba de los términos de los debates que tenían lugar en ese momento en Francia y en Europa. Su artículo "Derechos humanos, política y autoritarismo en el Cono Sur" sitúa la problemática de manera expresa en el marco de la concepción lefortiana

\footnotetext{
12 Agradezco a Susana Villavicencio, entonces integrante de la cátedra de Leis, esta información.

13 Este texto, incluido en Essais sur le politique, fue publicado en Argentina de manera separada en un pequeño volumen de Editorial Librería Hachette, Buenos Aires, 1988.

${ }^{14}$ Eduardo Rinesi recuerda también que - sin ser un autor que interesara especialmente a González - Lefort de todos modos estaba presente en una materia que dictaba aquel en la Carrera de Ciencia Política de la Universidad Nacional de Rosario en los años '80. El propio Rinesi recuerda haber leído por esos años con interés, por fuera de la materia de González, las presentaciones de Lefort y de Clastres al "Ensayo sobre la servidumbre voluntaria”, de Etienne de la Boétie, publicado en español por Tusquets en 1980.

15 Waldo Ansaldi (comp.), La ética de la democracia. Los derechos humanos como límite frente a la arbitrariedad, CLACSO, Buenos Aires, 1986. Norbert Lechner, quien murió tempranamente en 2004, tuvo un rol destacadísimo en la introducción de la temática de la democracia y los derechos en el debate de la izquierda intelectual latinoamericana.
} 
de la democracia, y apela asimismo a la reflexión de Hannah Arendt, tal como lo hace también por la misma época Lechner, con quien dialoga de manera destacada el texto de Gómez. ${ }^{16} \mathrm{Si}$ bien, hasta donde pude saber, José María Gómez permaneció desde entonces en Brasil y no tuvo mayor participación en el debate posterior en Argentina, la presencia de su texto en el libro de Clacso no deja de ser digna de mención. ${ }^{17}$

Un rápido paneo del exilio mexicano nos indica que Lefort estuvo casi ausente de las lecturas y debates de los círculos de intelectuales argentinos instalados allí. La revalorización de la democracia tomó principalmente el camino de la re-interrogación de la relación entre socialismo y democracia, y se produjo sobre todo en diálogo con los pensadores italianos y españoles involucrados en los avatares del eurocomunismo - recordemos que algunos de los principales animadores del medio de intelectuales exiliados, tales como José Aricó o Juan Carlos Portantiero, habían ellos mismos encabezado la aventura intelectual de alejamiento de la ortodoxia del Partido Comunista argentino en los años '60 a través de la Revista de Pasado y Presente. En esa dirección, Emilio de Ipola recuerda los encuentros fructíferos con Giacomo Marramao, Giuseppe Vacca, Christine Buci-Glucksmann o Ludolfo Paramio. Lefort estuvo casi ausente, decía, pero no del todo: Héctor Schmucler rememora haberse interesado por primera vez en sus años mexicanos en un autor que hasta entonces había lisa y llanamente desdeñado como lo había desdeñado todo el pensamiento tradicional de izquierda. "Lefort", me escribe, "no estaba en mi bibliografía y cuando entró levemente, era México hacia los 80. Entró, me parece, como confirmación de cosas que yo ya pensaba guiado por otros textos y por contundentes experiencias”. Y entró, además, favorecido por la intensa amistad que Schmucler entabló entonces con Andras Biro, antiguo militante comunista en Hungría que había tenido relevante participación en la revuelta de 1956. Tras la derrota, Biro se había marchado a Francia donde había establecido un fuerte vínculo con Lefort, Edgar Morin y Cornelius Castoriadis, esto es, con el núcleo que animaba la aventura de Socialismo o Barbarie. Biro, continúa Schmucler, lo había introducido a través de sus historias en "el clima político-intelectual que había compartido amistosamente (...) con ese grupo magnífico". Y el propio Emilio de Ipola advierte también que si bien Lefort no formó parte de sus intereses durante su estancia mexicana, en su

\footnotetext{
16 Entre las referencias bibliográficas del artículo de Gómez podemos mencionar, además de las ya citadas alusiones a Lefort, Arendt y Lechner, a Rawls, Habermas, Bobbio, Leo Strauss, Passerin d'Entreves, Octavio Paz o la Revista Esprit (además de relevantes intelectuales de la época en el Cono Sur).

17 Intenté sin éxito entrar en contacto con José María Gómez por mail, para recabar mayores datos sobre su interés en Lefort en aquellos años.
} 
breve paso por Paris en 1978 al salir de prisión había tenido ecos de un Lefort que ya no se le aparecía, como veinte años antes, como el mero figurante en la pelea con un Sartre indiscutidamente vencedor, sino como un autor de valía al que merecía la pena atender. ${ }^{18}$ Sería Emilio de Ipola, precisamente, uno de los intelectuales argentinos que en su regreso a la Argentina incorporaría bastante prontamente los textos de Lefort a la bibliografía de sus cursos. $^{19}$

Por fin, si centramos ahora nuestra mirada en la Argentina podremos completar el panorama de esta recepción en los años ' 80 . Ya hemos mencionado más arriba la aparición, en 1985, del libro La ética de la democracia editado por Clacso en Buenos Aires, y coordinado por Waldo Ansaldi. Cabe señalar que el libro fue el resultado de un encuentro académico centrado en la temática de los Derechos humanos, ${ }^{20}$ que tuvo lugar en Buenos Aires entre el 23 y el 25 de noviembre de 1983, en ocasión de la Asamblea General que debía elegir al nuevo Secretario General de Clacso. ${ }^{21}$ Ese nuevo secretario no sería otro que Fernando Calderón, quien como mencioné antes, había realizado su doctorado en Francia, y quien estaba familiarizado con el ambiente intelectual de la EHESS, y en particular, con quienes, como el propio Lefort, François Furet, Pierre Rosanvallon y otros intelectuales de talla se nuclearían a partir de 1984 en el Centro Raymond Aron. Al frente de Clacso Calderón jugaría, en los años '80, un rol destacado en el mayor conocimiento de la obra de Lefort en Argentina. Como señalé también,

18 Emilio de Ipola había leído, a fines de los '50, la polémica entre Sartre y Lefort en Les Temps Modernes por sugerencia de Oscar Massotta - y sartreano, como este, había dado razón sin más al primero. En la segunda mitad de los '60 conoció también, a través de Alain Touraine, la existencia de Socialisme ou Barbarie, aunque, involucrado en el althusserianismo no se interesó demasiado en ello. Recuerda en la conversación que en 1978, en su paso por Paris al salir de prisión, volvió a encontrarse con el nombre de Lefort en los libros que interesaban a dos amigas brasileras con las que recorría librerías: Les formes de l’histoire, de reciente aparición, y el Machiavel, publicado en 1972.

${ }^{19}$ Lefort está presente en los cursos y la bibliografía de E. de Ipola a partir de, por lo menos, 1987, en el dictado de la materia de Sociología sistemática y en el seminario sobre Durkheim y el lazo social, ambos en la Facultad de Ciencias Sociales de la UBA, y en el curso de posgrado dictado en la Universidad Nacional de Rosario. Asimismo, Susana Villavicencio recuerda que la concepción de la democracia de Lefort fue uno de los temas propuestos por de Ipola en el concurso para la selección de profesores para la cátedra de Sociología sistemática en la Facultad de Ciencias Sociales de la UBA en esos años.

20 Dicho encuentro, señala Ansaldi, fue el primer encuentro latinoamericano dedicado a la temática de los Derechos humanos.

21 La reunión tuvo lugar entre las elecciones en las que resultó electo Raúl Alfonsín, el 30 de octubre, y su asunción el 10 de diciembre de 1983. Entre los asistentes extra académicos estaban, recuerda Ansaldi, Elva Roulet (que había sido elegida vicegobernadora de la provincia de Buenos Aires) e Hipólito Solari Yrigoyen (asesor personal de Alfonsín y luego embajador plenipotenciario). 
encontramos en aquel libro editado por Ansaldi en 1985, la referencia a Lefort en tres autores distintos - el propio Ansaldi, José María Gómez y Norbert Lechner, sociólogo alemán radicado en Chile, quien tuvo una participación de gran relevancia en el renovado debate sobre la democracia y los derechos en Latinoamérica. ${ }^{22}$ Ansaldi rememora que tuvo un primer acercamiento a la obra de Lefort a través de Gómez, probablemente en aquel encuentro de noviembre de 1983, y que L'invention démocratique formó parte, por esos mismos años, de una importante donación de libros que realizó la Embajada de Francia a Clacso, de cuya selección participó personalmente. ${ }^{23} \mathrm{Si}$ bien, señala, su referencia a Lefort en el prólogo al libro responde más bien a la necesidad de exponer un campo de referencias, y no a alguna afinidad particular con esa obra, recuerda también haber leído con interés, siempre a principios de los ochenta, la edición en castellano del Discurso sobre la servidumbre voluntaria, que venía acompañado del texto "El nombre de Uno", de Lefort, como así también de otros dos escritos de Pierre Clastres y de Pierre Leroux. ${ }^{24}$

La segunda mitad de la década encontrará enseñando en la Universidad de Buenos Aires, y participando de los círculos intelectuales y académicos, a la casi totalidad de las personas que he mencionado en los apartados anteriores. Como ya advertí, Isidoro Cheresky y Emilio de Ipola tomarán a su cargo cátedras de la Facultad de Ciencias Sociales en las que la obra de Lefort se convertirá en bibliografía acostumbrada; Héctor Leis lo incorpora a su cátedra del Ciclo Básico Común. Lo mismo haremos Luis Alberto Quevedo y yo misma, primero como asistentes de Cheresky, luego cada uno en su propia enseñanza. Horacio González no lo incorpora como bibliografía, pero se refiere a él - Eduardo Rinesi recuerda que fue de boca de González que escuchó por primera vez su nombre. Señalé también que Lefort es citado en dos libros de gran circulación en esa década, Hegemony and Socialist Strategy de Laclau y Mouffe, y

\footnotetext{
${ }^{22}$ Los tres refieren a L'invention démocratique, y de manera particular a "Droits de l'homme et politique ». Gomez cita también la entrevista a Lefort realizada por Paul Thibaud y Philippe Raynaud, «La communication démocratique », aparecida en Revue Esprit 9-10, septiembre de 1979 (incluída posteriormente en Lefort, Claude, Le temps présent, Bélin, Paris, 2007, pp. 389-403).

23 A principios de los '80, Waldo Ansaldi integraba la Secretaría ejecutiva de Clacso y era el responsable del programa académico a científicos sociales perseguidos. Su primera lectura de Lefort, recuerda, fue el volumen en francés de L'Invention Démocratique donado a Clacso por la Embajada de Francia. Posteriormente, en 1984, compró en Rio de Janeiro la edición en portugués que cita en su prólogo a La ética de la democracia. Si bien Ansaldi no presentó una ponencia en el encuentro de Clacso de 1983, participó activamente de la organización y coordinó y prologó el volumen de 1985.

${ }^{24}$ La Boétie, Etienne, Discurso de la servidumbre voluntaria, (edición concebida y realizada por Miguel Abensour), Barcelona, Tusquets, 1980.
} 
Perón o Muerte de Silvia Sigal y Eliseo Verón. Sin convertirse, lejos de ello, en un autor de presencia destacada en los debates habituales de los círculos de pensamiento político, más centrados alrededor de los grandes nombres de la ciencia política de raigambre norteamericana, el nombre de Lefort comienza no obstante en esos años a aparecer como una referencia relevante no solo para quienes revisan - con o contra Lefort - su propios modos de "ser de izquierda", sino también para quienes no se sienten del todo a gusto con aquellas corrientes dominantes del pensamiento político. Es posible decir - retomando la doble diferenciación que el propio Lefort establece, al comienzo de "El problema de la democracia", con el marxismo y la ciencia política, que, si para quienes lo comenzaron a leer en el exilio, la ruta que les trazó Lefort fue sobre todo la de salida de una filosofía de la historia que había perdido toda conexión con el pensamiento de aquello que acontecía, quienes se interesaron en él en los segundos '80 en Argentina la frecuentación de la obra de Lefort proveyó sobre todo la posibilidad de pensar lo político por fuera de su aplanamiento por parte de la ciencia política dominante. ${ }^{25}$

Es en ese contexto - de un interés a la vez restringido geográfica y numéricamente, pero muchas veces intenso entre quienes se nutren de su obra - que podemos situar la presencia en 1988 de Claude Lefort, invitado por Clacso - una vez más, por intermedio de Fernando Calderón-, en Buenos Aires, que incluyó un encuentro con intelectuales en el subsuelo de la librería Gandhi de la calle Montevideo - del que participaron, entre otros, Carlos Altamirano, Emilio de Ipola, Jorge Tula, Juan Carlos Portantiero y José Aricó, todos ellos, por otra parte, figuras notables del Club de Cultura Socialista y de la revistas La Ciudad Futura y Punto de Vista - y una conferencia en la Facultad de Ciencias Sociales, como así también la edición en 1990 de una versión de La invención democrática, que reunirá textos del volumen homónimo de 1980 y del más reciente Essais sur le politique de 1986, por parte de la editorial Nueva Visión, bajo la responsabilidad de Carlos Altamirano.

Llegamos así a 1990... y aquí me detengo. Si miro hacia atrás pienso que el panorama probablemente no haya variado mucho; aunque por mi parte tengo bajo mi dirección una tesis sobre Lefort, y tengo o he tenido por lo menos tres más que se han ocupado de él de manera destacada, aunque existen destacados colegas de generaciones sucesivas - pienso, entre otros, en Martín Plot o Lucas Martín - que se han interesado fuertemente por su obra probablemente movidos por algunos de los hilos que acabo de deshilvanar, Lefort sigue siendo entre nosotros un autor bastante poco frecuentado. Aún así, me digo que algunos de nosotros hemos visto

\footnotetext{
${ }^{25}$ Esto último fue apareciendo con claridad a partir de las entrevistas con Luis A. Quevedo y Carlos Altamirano.
} 
pasar por nuestros cursos, en estas tres décadas, centenares de estudiantes a los que hemos forzado a interesarse en él, que nosotros mismos, y luego otros, se han referido a Lefort en sus escritos, que la lectura más masiva de Laclau y Mouffe también ha llevado a hacer del nombre de Lefort algo más familiar... y me digo también que algo de eso, seguramente, habrá quedado no solo en aquellos estudiantes que se agruparon alrededor nuestro como becarios o investigadores, sino también, quien sabe, en algún otro que - desde algún fondo de su memoria - recuerda que alguien, en algún texto, lo instaba a preguntarse, por ejemplo, qué hay de la diferencia entre servidumbre y libertad.

\section{Referências bibliográficas}

ANSALDI, Waldo. (comp.). La ética de la democracia. Los derechos bumanos como límite frente a la arbitrariedade. Buenos Aires, CLACSO, 1986.

CALDERÓN, Fernando (comp.), Socialismo, autoritarismo y democracia. Lima, IEP/Clacso, 1989.

HABIB, Claude et MOUCHARD, Claude (eds), La démocratie à l'oenure. Autour de Claude Lefort. Paris, Esprit, 1993.

LA BOÉTIE, Etienne, Discurso de la servidumbre voluntaria, (edición concebida y realizada por Miguel Abensour), Barcelona, Tusquets, 1980.

LACLAU, Ernesto and MOUFFE, Chantal, Hegemony and Socialist Strategy. London, Verso, 1985.

LEFORT, C. Essais sur le politique, Editorial Librería Hachette, Buenos Aires, 1988. Le temps présent. Paris, Bélin, 2007.

LEIS, Héctor. El movimiento por los derechos bumanos y la politica argentina. Centro Editor de América Latina, 1989.

SIGAL, Silvia y VERÓN, Eliseo. Perón o Muerte. Buenos Aires, Eudeba, 1986. 